REVIEW

\title{
Liver transplantation for hepatitis $C$ virus related liver disease
}

\author{
I Gee, G Alexander
}

Postgrad Med J 2005;81:765-771. doi: 10.1136/pgmj.2005.034082

Liver transplantation is a useful treatment for end stage liver disease of all aetiologies but recurrent disease presents an ongoing challenge, particularly for hepatitis $\mathrm{C}$ virus (HCV) where recurrence is almost universal. Immunosuppression is needed for all patients after transplantation and should be tailored to the individual patient, with particular problems being noted for those with HCV. The longer term effects of immunosuppression, particularly renal failure and the adverse effects of certain treatments on the liver graft, have become more important as survival improves and results are studied for longer periods after transplantation.

See end of article for authors' affiliations .....................

Correspondence to: Dr I Gee, Department of Gastroenterology, Level 2 Windsor Building, Leicester Royal Infirmary, Infirmary Square, Leicester LE1 5WW, UK; igee@ doctors.org.uk

Submitted

23 February 2005 Accepted 20 April 2005 iver transplantation was first performed in $1963^{1}$ as an experimental treatment for end -stage liver disease, when three patients were transplanted, all of whom died within three weeks. Since then it has become an established treatment resulting in improved quality of life, ${ }^{2}$ with 675 transplants from cadaveric donors taking place in the UK in 2001 and 706 in 2002. ${ }^{3}$ These figures include a small number of patients transplanted in the UK who are not eligible for NHS treatment. Liver transplant activity has increased substantially compared with 10 years ago when 502 liver transplants were performed in 1992. Early (one year) survival has improved to $88 \%$ for the period 1998-1999, with 73\% three year survival for the period 1996-1997, and 64\% five year survival for the period 1994-1995. ${ }^{3}$ This improvement is probably attributable to a combination of factors such as improved surgical and anaesthetic technique, changes in medical management after transplantation, the improved recognition of other harmful factors like hypertension, and improved selection of patients in whom liver transplantation is probably not appropriate such as those with multiple large tumours or cholangiocarcinoma.

Indications for transplantation include chronic liver failure attributable to most chronic parenchymal liver disorders that result in cirrhosis or hepatocellular carcinoma and acute liver failure. These include viral hepatitis (B and C), primary biliary cirrhosis, primary sclerosing cholangitis, cryptogenic cirrhosis, metabolic liver disease, alcoholic cirrhosis, autoimmune hepatitis, biliary atresia, $\alpha_{1}$ antitrypsin deficiency, haemochromatosis and acute liver failure attributable to paracetamol overdose, autoimmune hepatitis, hepatitis A, B, and E, or drugs (see fig 1).

Because of its success in treating liver failure resulting from these conditions, there is a shortage of organs available for transplantation (there were 158 patients on the liver transplant waiting list at the end of 2001, 163 at the end of 2002) and there is therefore much debate about who should receive this scarce resource. Re-transplantation already accounts for some of the transplant activity and as long term survival improves in transplant recipients, graft failure due to recurrent disease will also rise. This is particularly true for hepatitis $\mathrm{C}$, which is now the commonest indication for liver transplantation worldwide. Re-transplantation is well known to be associated with higher complication rates and lower patient and graft survival for all conditions. ${ }^{4}$ In patients with graft failure due to recurrent hepatitis $C$, transplantation after the development of decompensation of the graft gave a one year survival rate of $41 \% .^{56}$ This has resulted in much research being aimed at preserving graft function. As survival improves ${ }^{7}$ and the number of available treatment options increases (such as new immunosuppressive and antiviral drugs), the long term effects of the different available treatments and their side effects, such as renal failure, ${ }^{89}$ become more apparent and more important.

This review focuses on liver transplantation for hepatitis C virus (HCV) related liver disease and the different immunosuppression agents used.

\section{HEPATITIS C VIRUS}

HCV is an increasingly common chronic viral infection affecting the liver. Estimates of the number of people infected in the UK range from 200000 to 400000 although the true number remains unknown. ${ }^{10}$ It is mostly spread by blood transfer and is therefore common among users of injected drugs. ${ }^{11}$ It is also prevalent in patients who have received blood transfusions or other blood products before blood was screened for hepatitis C infection. This includes patients with haemophilia who received many transfusions or blood products before $1985 .{ }^{12}$ There may also be a small risk of transfer by sexual intercourse that has been quantified at less than $5 \%$ to spouses of infected patients ${ }^{13}$ although the precise magnitude of this risk has not been fully established.

Once infected, most people become chronic HCV carriers and develop chronic hepatitis. ${ }^{14}$ It

Abbreviations: $\mathrm{HCV}$, hepatitis $\mathrm{C}$ virus; MMF, mycophenolate mofetil; NF-AT, nuclear factor of activated $T$ cells 
causes liver fibrosis in a significant proportion of those infected, with the median time from infection to cirrhosis estimated to be 30 years. ${ }^{15}$ The biggest determinants of the rate of fibrosis progression are the age at infection, with older ages being associated with more rapid progression of disease, alcohol consumption greater than $50 \mathrm{~g}$ per day, male sex, ${ }^{15}$ and body mass index. There may be a link with viral genotype $1,{ }^{16}$ but this is less certain.

When infection has been established by the presence of the hepatitis $\mathrm{C}$ antibody and viral RNA in serum, a liver biopsy is usually performed to assess the degree of liver damage. Any patient with significant fibrosis or inflammation is usually offered treatment with interferon alfa and ribavirin. For types $\mathrm{l}$ and $4 \mathrm{HCV}$ this is continued for one year and for types 2 and 3 it is continued for six months. ${ }^{10}$ More recently pegylated interferon has been used in combination with ribavirin with some improvement in cure rates. Current literature suggests a cure rate for genotypes 1 and 4 of up to $41 \%$ and for genotypes 2 and 3 of up to $80 \% .{ }^{17}$

When cirrhosis has developed in an infected liver, the disease can progress to hepatic decompensation over a period of up to 10 years during which there is a significant risk of evolving hepatocellular carcinoma. ${ }^{18}$ These situations carry a poor prognosis for which the only effective treatment is liver transplantation.

\section{RECURRENT DISEASE}

After transplantation for HCV related liver disease, graft infection is almost universal. ${ }^{19}$ Treatment for acute rejection (in contrast with acute rejection itself) and a higher cumulative corticosteroid dose have a detrimental effect on graft survival. Sheiner et al showed a clear correlation between time to recurrence of biopsy confirmed HCV and treatment for acute rejection. ${ }^{20}$ They found that patients without acute rejection had the lowest levels of hepatitis recurrence in their graft $(18 \%)$, patients with one episode of

\section{Key points: hepatitis C}

- Hepatitis C affects between 200000 and 400000 people in the UK

- It is the commonest indication for liver transplantation worldwide

- Progression to cirrhosis is slow but made faster by alcohol consumption of more than $50 \mathrm{~g}$ per day

- Treatment is with interferon (or pegylated interferon) and ribavirin (efficacy depends on viral genotype)

rejection had a risk of recurrence of $42 \%$, and patients with multiple episodes of rejection had a recurrence risk of $70 \%$. Patients with corticosteroid resistant rejection treated with OKT3 had a recurrence risk of $71 \%$. Berenguer et al also found a link between treatment of acute rejection and recurrence of $\mathrm{HCV}$ in the graft. ${ }^{21}$ Although they found that there was no relation at one year after transplantation, a significant relation had developed by two years. This was stronger in patients who had had multiple episodes of acute rejection. They also found that cumulative corticosteroid doses were higher in patients who developed chronic graft hepatitis. Only four patients were treated with OKT3 in this series, but three of them developed moderate or severe hepatitis by one year after transplantation and two had died by two years after transplantation.

The drugs used for immune suppression also play a part in the progression of graft disease. ${ }^{22}{ }^{23}$ Initial immunosuppression and longer duration of corticosteroids have been shown to correlate with fibrosis progression in the graft. ${ }^{22}$ Papatheodoridis et al found that immunosuppression with a single agent correlated with higher levels of HCV RNA at three months but that at 12 months high HCV RNA levels

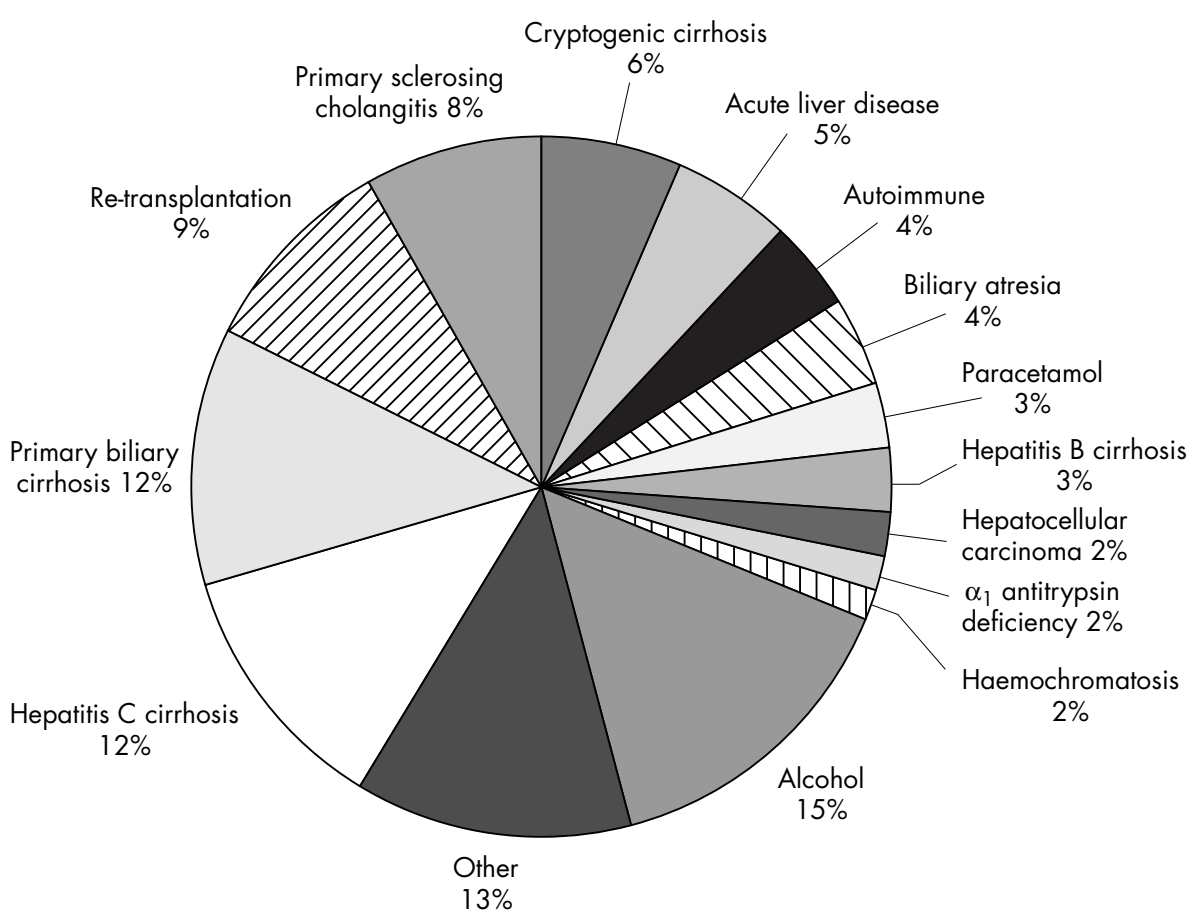

Figure 1 Indications for liver transplantation in UK NHS patients with percentages in the calendar year 2002. The total number of transplants performed was 665 . 
correlated only with longer duration of corticosteroid treatment. ${ }^{24}$ The HCV RNA level at 12 months also correlated with the severity of fibrosis at 12 months. A second study from the same group found that initial immunosuppression using multiple agents resulted in more severe graft fibrosis three years after transplantation ${ }^{22}$ although the patients with the heavier immunosuppression are those who also had corticosteroids as part of their initial treatment.

The use of the interleukin 2 receptor antagonist daclizumab together with mycophenolate mofetil (MMF) has been shown to cause more rapid progression of HCV related fibrosis. ${ }^{23}$ A study by Nelson et al of 41 patients (21 with HCV) treated with MMF and daclizumab found that there was a detrimental effect on the patients with HCV. Patients with HCV had a shorter time to histological recurrence of hepatitis and jaundice and greater histological activity at one year after transplantation, with $45 \%$ having developed advanced disease by this stage.

Regimens including azathioprine have been associated with reduced histological recurrence. ${ }^{25}$ Hunt et al studied 65 patients with HCV treated with calcineurin inhibitor and prednisolone who were transplanted over a 15 year period. Seventeen of them also had azathioprine included in their treatment regimen. They found that regimens including azathioprine had a lower rate of histological recurrence and disease progression. There was no difference seen between the calcineurin inhibitors used.

This progression of HCV related disease may be much more rapid than that seen in native liver $^{26} 27$ with fibrosis rates increasing in recent years. ${ }^{5}$ In several studies it has been shown that the progression of fibrosis is more rapid, varying from a median time to cirrhosis of 1.6 years to 13 years. ${ }^{26} 28-30$ Berenguer et al also found that the rate of fibrosis progression was increasing over the time period studied with time to cirrhosis falling from $9.8-13$ years in 1990-1991 to 1.6 years in 1996. ${ }^{5}$ Fibrosis development can therefore progress much more rapidly in some patients.

Donor age has recently been recognised to be one of the most important determinants of graft disease after transplantation for HCV related cirrhosis. The study by Wali et a ${ }^{30}$ estimated that with a donor aged under 40 years old fibrosis would progress at 0.6 stages per year (cirrhosis was stage 6) with a median time to cirrhosis of 10 years. If the donor was aged 50 or over, the progression rate was 2.7 stages per year with a median time to cirrhosis of 2.2 years. Berenguer et al confirmed the finding that increasing donor age was associated with more rapid progression to cirrhosis but did not estimate the rate for different donor ages. ${ }^{31}$ A third study concluded that donor age was the most significant predictor of graft failure in their series of 93 patients. ${ }^{32}$ For each decade increase in donor age the relative risk of graft failure rose significantly. The findings in these comparatively small cohorts of patients have subsequently been confirmed in larger cohorts. Neumann et $a l^{33}$ described 183 patients and Rifai $e^{2} a^{34} 270$ patients with hepatitis C in whom increasing donor age had an adverse effect on survival and fibrosis development. Lake et $a l^{35}$ described 3463 patients reported to the Scientific Registry of Transplant Recipients in America and found that donor age of over 40 was strongest predictor of graft loss and death in patients with hepatitis C. The study by Rifai $e a^{34}$ also suggested that there may be a detrimental effect of donor age irrespective of hepatitis C status, a finding that was also seen in a study by Russo et $a^{36}$ looking at the United Network for Organ Sharing database in America.

Drugs aimed at reducing the viability of HCV such as interferon and ribavirin have been disappointing. It is now accepted that the combination of interferon and ribavirin is the treatment of choice for HCV infection in native liver and several studies have been performed to see if viral clearance is possible after liver transplantation. This combination of drugs has been shown to be effective in some studies, but the results are mixed. Although some studies show an improvement in biochemistry there seems to be no impact on the progression of fibrosis in serial biopsies. ${ }^{37-42}$ Furthermore, many studies have found that the combination of interferon and ribavirin is poorly tolerated in this group ${ }^{39} 41{ }^{43-45}$ with one of these studies finding that $66 \%$ of patients needed dose modification or cessation of treatment. ${ }^{45}$

The accelerated fibrosis seen after transplantation in patients with HCV compares poorly with patients with HCV in native liver where Poynard et al estimated that development of cirrhosis may take 30 years. ${ }^{15}$ Fibrosis in this group of 2235 patients progressed at a rate of 0.133 stages per year (cirrhosis was stage 4).

\section{IMMUNE SUPPRESSION}

Immune suppression is essential after organ transplantation to prevent the host immune system rejecting the organ. There are now many different drugs used including calcineurin inhibitors (cyclosporine and tacrolimus), sirolimus, antiproliferative drugs (azathioprine, mycophenolate mofetil), corticosteroids, and various lytic or blocking monoclonal antibodies.

Immunosuppression is started during the transplant operation and continued thereafter, usually for life. Because of the long duration over which the patient takes the drugs, side effects are important but may only become apparent after several years. The effect of the drug on the liver graft is also important, particularly now that patients survive longer.

\section{Calcineurin inhibitors}

Cyclosporine was the first calcineurin inhibitor to become available in the late 1970s. In combination with improved operative and anaesthetic techniques it created a milestone in transplantation by permitting much improved graft and patient survival compared with previous treatments that had relied on a combination of prednisolone and azathioprine. ${ }^{46-48}$ It acts by binding cyclophylin and the resulting complex inhibits the activity of calcineurin phosphatase. This in turn prevents dephosphorylation of nuclear factor of activated $\mathrm{T}$ cells (NF-AT) resulting in reduced production of interleukin 2 by T cells. Interleukin 2 stimulates B cells and natural killer cells to become activated, thus damaging the allograft.

Many studies have been done looking at how best to use cyclosporine and for several years it was the mainstay of treatment for all solid organ transplants. There is currently some debate about how to monitor patients; trials are underway based on monitoring the drug level at two hours

\section{Key points: recurrent disease}

- Hepatitis $C$ recurrence is almost universal in liver grafts

- Fibrosis progression is more rapid than in native liver

- Median time to cirrhosis is 10 years

- Donor age and treatment for acute rejection las compared with acute rejection itself) are important determinants of the rate of fibrosis progression

- Fibrosis rates have increased in recent years

- Interferon and ribavirin are poorly tolerated after transplantation and do not change the rate of fibrosis progression

- Current practice is to use calcineurin inhibitor monotherapy (usually tacrolimus) as the mainstay of immunosuppression 
after dose compared with conventional practice, which is to measure the trough level. The aim of this newer approach is to try and minimise the side effects, but different pharmacokinetics between patients are likely to cause problems because time from dosing to peak level is variable and not predictable. The main side effects of cyclosporin are renal impairment (which may cause renal failure), weight gain, hypertension, hyperlipidaemia, hyperuricaemia, tremor, headache, hirsutism, gingival hyperplasia, and diabetes mellitus.

Tacrolimus, also a calcineurin inhibitor, was first used in the late 1980s and binds FK-binding protein 12 within the cell. This complex acts on the enzyme calcineurin phosphatase, resulting in a similar mode of action to cyclosporin. The side effects are similar, causing renal impairment (which may cause renal failure), weight gain, hypertension, hyperlipidaemia, hyperuricaemia, tremor, headache, and diabetes mellitus, although it does not cause hirsutism and gingival hyperplasia.

Tacrolimus was initially promoted as a rescue therapy for failed treatment with cyclosporin but is now often used as first line therapy. There have been several studies comparing the efficacy of the calcineurin inhibitors in liver transplantation. In European and American studies ${ }^{49-51}$ there is a clear but modest benefit of tacrolimus over cyclosporine in terms of early graft and patient survival, with lower acute and chronic rejection rates but more side effects. Longer term follow up is awaited with interest. A recent randomised trial comparing cyclosporin with tacrolimus for initial immunosuppression in the first year after transplantation found no difference between the two drugs assessed by liver biopsy. ${ }^{52}$ Patients sometimes switch between the drugs because side effects vary from patient to patient with each drug.

\section{Mycophenolate mofetil}

MMF is an ester pro-drug of mycophenolic acid, an antiproliferative agent that predominantly affects lymphocyte proliferation. It inhibits the action of inosine monophosphate dehydrogenase in a non-competitive manner (this is the same enzyme that is competitively inhibited by ribavirin). It has been used predominantly as an add on treatment with a calcineurin inhibitor to try and improve outcome or as a means of reducing calcineurin inhibitor dose in patients with renal dysfunction. It has also been used as monotherapy in patients with renal failure.

MMF has also been trialled for use in $\mathrm{HCV}^{53-55}$ because of a possible antiviral effect as it is known to inhibit the same enzyme as ribavirin (although by a different method). None of these trials have found an improved survival outcome using MMF either in combination with a calcineurin inhibitor or without a calcineurin inhibitor, nor had a clear antiviral effect. It was also noted that MMF did not change the response to antiviral treatment. Two trials of patients with hepatitis $\mathrm{C}$ have shown a detrimental effect of MMF use $^{32} 56$ although one trial found a positive effect using MMF with less inflammation and fibrosis seen in biopsies of patients taking MMF. ${ }^{.7}$ Its role is therefore not clear and it is currently used as a second line drug. The main side effects are bone marrow suppression, nausea, and diarrhoea.

\section{Azathioprine}

Azathioprine used to be the most commonly used immunosuppressant before the development of cyclosporine and works by inhibiting the differentiation and proliferation of $\mathrm{B}$ and $\mathrm{T}$ lymphocytes by interfering with RNA and DNA synthesis. Its main problem is lymphopenia, especially in the early postoperative period. It has been largely superseded by the calcineurin inhibitors as the mainstay of immunosuppressive therapy after transplantation, but has an important part to play alongside calcineurin inhibitors in patients transplanted for autoimmune liver disorders. It is however often used in the first few months after transplantation in addition to a calcineurin inhibitor and may improve outcome when used in combination therapy after transplantation for HCV related cirrhosis. ${ }^{25} 5658$

\section{OKT3}

OKT3 is an anti-CD3 murine monoclonal antibody that is directed against the CD3 complex expressed on mature $\mathrm{T}$ cells. It has been used as primary immunosuppression after transplantation but is now generally used only to treat corticosteroid resistant rejection. It is associated with a poor outcome and severe recurrence of hepatitis if used in HCV. ${ }^{21} 59$ Rosen et al retrospectively analysed 19 patients who received OKT3 for corticosteroid resistant rejection and compared them with 33 patients who received corticosteroids for acute rejection but no OKT3. ${ }^{59}$ They found that there was a shorter time to HCV recurrence and a more severe hepatitis in those patients who received OKT3 and that these patients were more likely to develop cirrhosis during follow up.

ATG is a polyclonal antibody to all human thymocytes but is generally thought to be much safer to use in corticosteroid resistant acute rejection. It is currently the treatment used in this situation.

Clearly $\mathrm{T}$ cell antibodies have a part to play in patients in whom pulsed corticosteroids cannot control acute rejection, but there seems to be no advantage to their routine use and they should be used with extreme caution in patients with HCV.

\section{Corticosteroids}

Corticosteroids are potent anti-inflammatory drugs that act through intracellular receptors to regulate gene transcription. They were the first drugs used in combination with azathioprine to control rejection. Until the discovery of cyclosporine this combination provided the mainstay of treatment for the prevention of rejection. The main problem with corticosteroids is their numerous side effects. Many of the side effects are, however, the result of longer term use and corticosteroids are still useful drugs, particularly if they are used sparingly. They are used as part of the initial immunosuppression after transplantation and in short courses of large doses to treat acute rejection. Specific problems with corticosteroids after transplantation have been reported with HCV. The rate of fibrosis progression in the graft has been shown to be faster with higher cumulative doses of corticosteroids ${ }^{524}$ and there is some evidence that the rate of withdrawal of corticosteroids may have an effect on the graft. Brillanti et al studied a retrospective cohort of patients with HCV and found that those who were taking higher doses of prednisolone at 12 months and were therefore having their dose tapered very slowly had less recurrence of hepatitis. ${ }^{60}$ This finding is controversial and contradicts the findings of many other studies that have shown a link only to total corticosteroid dose and treatment of acute rejection. The result could have arisen because the end points used were

Immunosuppression agents commonly used in liver transplantation

- Calcineurin inhibitors (cyclosporin, tacrolimus)

- Prednisolone

- Azathioprine

- Mycophenolate mofetil

- Sirolimus

- Antibodies (ATG, OKT3) 
biochemical rather than histological ${ }^{61}$ and most believe that histology is the most critical outcome measure. ${ }^{62}$ There is also evidence from two other studies that corticosteroids should not be stopped early. Berenguer et al found that stopping corticosteroids in the first year after transplantation led to worse fibrosis ${ }^{56}$ and Somanakis et al found that patients maintained on corticosteroids developed less severe fibrosis. ${ }^{58}$ The role of corticosteroids beyond three months after transplantation therefore remains controversial.

There is evidence that corticosteroids are also harmful for those with hepatitis B virus related liver disease.

\section{Sirolimus}

Sirolimus is a macrolide immunosuppressant derived from Streptomyces hygroscopicus. It was initially investigated as a chemotherapeutic agent and for its antifungal properties but caused too much immunosuppression to be clinically useful. It was subsequently investigated as an immunosuppressive agent and was first used in liver transplantation in the late 1990s. ${ }^{63}$ It acts by binding FK-binding protein 12, which in turn binds the mammalian target of rapamycin (mTOR) protein (rather than binding calcineurin as tacrolimus does), blocking cytokine mediated and ligand binding mediated signal transduction, by inhibition of the p70 S6 kinase enzyme. It causes arrest at the Gl/S phase of the cell cycle.

It has no effect on calcineurin phosphatase activity and therefore has a different side effect profile to the calcineurin inhibitors ${ }^{64-69}$ There is no direct nephrotoxicity and one particular benefit in relation to calcineurin inhibitors is the improvement in renal function after switching to sirolimus. ${ }^{70-72}$ Known side effects include lymphocele development, impaired wound healing, abdominal and bony pains, diarrhoea, oedema, oral ulceration, anaemia, leucopoenia, and the nephrotic syndrome. It has recently been licensed as monotherapy for use in renal transplantation but remains unlicensed for use after liver transplantation.

A study done on a rat model of hepatic fibrosis also suggested that sirolimus exerts an antifibrotic effect. ${ }^{73}$ Rats were given carbon tetrachloride and it was found that when sirolimus was given in addition to carbon tetrachloride hepatic fibrosis did not develop as it did in the control group. It was also found that sirolimus inhibited the proliferation of hepatic stellate cells stimulated by platelet derived growth factor in a cell culture model, leading the authors to suggest

\section{Five key references}

- Berenguer M, Ferrell L, Watson J, et al. Hov-related fibrosis progression following liver transplantation: increase in recent years. J Hepatol 2000;32:673-84.

- Poynard T, Bedossa P, Opolon P. Natural history of liver fibrosis progression in patients with chronic hepatitis C. The OBSVIRC, METAVIR, CLINIVIR, and DOSVIRC groups. Lancet 1997;349:825-32.

- Boker KH, Dalley G, Bahr MJ, et al. Long-term outcome of hepatitis $c$ virus infection after liver transplantation. Hepatology 1997;25:203-10.

- Feray C, Caccamo L, Alexander GJ, et al. European collaborative study on factors influencing outcome after liver transplantation for hepatitis C. European concerted action on viral hepatitis (eurohep) group. Gastroenterology 1999;117:619-25.

- Wali M, Harrison RF, Gow PJ, et al. Advancing donor liver age and rapid fibrosis progression following transplantation for hepatitis C. Gut 2002;51:248-52. that this could be a possible mechanism of action. A previous study performed by the same group investigating the effect of tacrolimus on the development of liver fibrosis in rats found that administration of tacrolimus with carbon tetrachloride caused an increase in the amount of fibrosis. ${ }^{74}$ Two other studies performed in culture models have also found that sirolimus may have an antifibrotic effect. A study using a fibroblast cell culture model found that in the presence of platelet derived growth factor or basic fibroblast derived growth factor, fibroblast proliferation was reduced. ${ }^{75} \mathrm{~A}$ second study using a tissue slice growth model found that collagen deposition and fibrosis development in the slice of cultured liver tissue was reduced in a dose dependent fashion in the presence of sirolimus. ${ }^{76} \mathrm{~A}$ role for sirolimus in graft fibrosis, especially in relation to HCV infection, is under investigation currently.

\section{Current practice at Addenbrooke's hospital}

Immunosuppression after liver transplantation at Addenbrooke's hospital usually comprises three types of drugs. Corticosteroids (methyl prednisolone) are given intraoperatively, with intravenous azathioprine and tacrolimus postoperatively. Oral drugs are substituted as soon as possible. These are given on a daily basis according to weight and trough drug level in the case of tacrolimus. The corticosteroid dose is rapidly tapered so that all corticosteroids should have stopped by three months after transplantation. The azathioprine is stopped six months after transplantation (except in the case of transplantation for autoimmune hepatitis) and the patients continue on tacrolimus monotherapy with a target trough dose range of 5$10 \mathrm{ng} / \mathrm{ml}$.

Acute rejection is treated with methyl-prednisolone $500 \mathrm{mg}$ bolus intravenous injections for three sequential days. This can be repeated if necessary before using specific antibodies such as ATG for biopsy verified recurrent acute rejection.

\section{QUESTIONS (TRUE (T)/FALSE (F); ANSWERS AT END OF REFERENCES)}

1. Hepatitis $\mathrm{C}$ recurrence in liver grafts is rare

2. Fibrosis in hepatitis $\mathrm{C}$ infected liver grafts is accelerated when compared with native liver

3. Standard treatment for hepatitis C (interferon and ribavirin) is effective after liver transplantation

4. Patients with hepatitis $C$ infected liver grafts should be treated with large doses of corticosteroids after transplantation

5. Transplantation for hepatitis $\mathrm{C}$ related cirrhosis is becoming increasingly common worldwide

\footnotetext{
Authors' affiliations

I Gee, Department of Gastroenterology, Leicester Royal Infirmary, Leicester, UK

G Alexander, Department of Medicine, University of Cambridge School of Clinical Medicine, Addenbrooke's Hospital, Cambridge, UK

Funding: none.

Conflicts of interest: none declared.

\section{REFERENCES}

1 Starzl TE, Marchioro TL, Von Kaulla KN, et al. Homotransplantation of the liver in humans. Surg Gynecol Obstet 1963;1 17:659-76.

2 Lowe D, O'Grady JG, McEwen J, et al. Quality of life following liver transplantation: a preliminary report. J R Coll Physicians Lond 1990;24:43-6.

3 UK Transplant published statistics. http://www.uktransplant.org.uk
} 
4 Biggins SW, Beldecos A, Rabkin JM, et al. Retransplantation for hepatic allograft failure: Prognostic modeling and ethical considerations. Liver Transplantation 2002;8:313-22.

5 Berenguer M, Ferrell L, Watson J, et al. Hcv-related fibrosis progression following liver transplantation: increase in recent years. J Hepatol 2000;32:673-84

6 Facciuto M, Heidt D, Guarrera J, et al. Retransplantation for late liver graft failure: predictors of mortality. Liver Transplantation 2000;6:174-9.

7 Jamieson NV, Friend PJ, Johnston PS, et al. Orthotopic liver transplantation at Addenbrooke's Hospital Cambridge 1968 to 1991. Clin Transpl 1991;5:119-25.

8 Fisher NC, Nightingale PG, Gunson BK, et al. Chronic renal failure following liver transplantation: a retrospective analysis. Transplantation 1998;66:59-66.

9 Cohen AJ, Stegall MD, Rosen CB, et al. Chronic renal dysfunction late after liver transplantation. Liver Transplantation 2002;8:916-21.

10 Booth JC, O'Grady J, Neuberger J. Clinical guidelines on the management of hepatitis C. Gut 2001;49(suppl 1):11-21.

11 Zuckerman AJ. The elusive hepatitis C virus. BMJ 1989;299:871-3.

12 Franchini M, Capra F, Tagliaferri A, et al. Update on chronic hepatitis C in hemophiliacs. Haematologica 2002;87:542-9.

$13 \mathrm{Kao} \mathrm{JH}$, Chen PJ, Lei MY, et al. Sexual transmission of HCV. Lance 1993;342:626

14 Alter MJ, Margolis HS, Krawczynski K, et al. The natural history of community-acquired hepatitis $C$ in the United States. The Sentinel Counties Chronic non-A, non-B Hepatitis Study Team. N Engl J Med 1992;327:1899-905

15 Poynard T, Bedossa P, Opolon P. Natural history of liver fibrosis progression in patients with chronic hepatitis C. The OBSVIRC, METAVIR, CLINIVIR, and DOSVIRC groups. Lancet 1997;349:825-32.

16 Wright M, Goldin R, Fabre A, et al. Measurement and determinants of the natural history of liver fibrosis in hepatitis $C$ virus infection: a cross sectional and longitudinal study. Gut 2003:52:574-9.

17 Manns MP, McHutchison JG, Gordon SC, et al. Peginterferon alfa-2b plus ribavirin compared with interferon alfa- $2 b$ plus ribavirin for initial treatment of chronic hepatitis C: a randomised trial. Lancet 2001;358:958-65.

18 Fattovich G, Giustina G, Degos F, et al. Morbidity and mortality in compensated cirrhosis type C: a retrospective follow-up study of 384 patients. Gastroenterology 1997;112:463-72.

19 Wright T, Donegan E, Hsu H, et al. Recurrent and acquired hepatitis $\mathrm{C}$ viral infection in liver transplant recipients. Gastroenterology 1992;103:317-22.

20 Sheiner PA, Schwartz ME, Mor E, et al. Severe or multiple rejection episodes are associated with early recurrence of hepatitis $C$ after orthotopic liver transplantation. Hepatology 1995;21:30-4.

21 Berenguer $M$, Prieto $M$, Cordoba J, et al. Early development of chronic active hepatitis in recurrent hepatitis $\mathrm{c}$ virus infection after liver transplantation: association with treatment of rejection. J Hepatol 1998;28:756-63.

22 Papatheodoridis GV, Davies S, Dhillon AP, et al. The role of different immunosuppression in the long-term histological outcome of HCV reinfection after liver transplantation for HCV cirrhosis. Transplantation 2001;72:412-18.

23 Nelson DR, Soldevila-Pico C, Reed A, et al. Anti-interleukin-2 receptor therapy in combination with mycophenolate mofetil is associated with more severe hepatitis $C$ recurrence after liver transplantation. Liver Transplantation 2001:7:1064-70.

24 Papatheodoridis GV, Barton SG, Andrew D, et al. Longitudinal variation in hepatitis c virus (HCV) viraemia and early course of HCV infection after liver transplantation for HCV cirrhosis: the role of different immunosuppressive regimens. Gut 1999:45:427-34.

25 Hunt J, Gordon FD, Lewis WD, et al. Histological recurrence and progression of hepatitis $C$ after orthotopic liver transplantation: influence of immunosuppressive regimens. Liver Transplantation 2001;7:1056-63.

26 Feray C, Gigou M, Samuel D, et al. The course of hepatitis c virus infection after liver transplantation. Hepatology 1994;20:1137-43.

27 Boker KH, Dalley G, Bahr MJ, et al. Long-term outcome of hepatitis c virus infection after liver transplantation. Hepatology 1997;25:203-10.

28 Bourgeois N. Hepatitis c recurrence after liver transplantation. Acta Gastroenterol Belg 1999;62:428-31.

29 Feray C, Caccamo L, Alexander GJ, et al. European collaborative study on factors influencing outcome after liver transplantation for hepatitis $C$. European concerted action on viral hepatitis (eurohep) group. Gastroenterology 1999;117:619-25.

30 Wali M, Harrison RF, Gow PJ, et al. Advancing donor liver age and rapid fibrosis progression following transplantation for hepatitis $C$. Gut 2002;51:248-52

31 Berenguer $M$, Prieto $M$, Juan FS, et al. Contribution of donor age to the recent decrease in patient survival among HCV-infected liver transplant recipients. Hepatology 2002;36:202-10.

32 Burak KW, Kremers WK, Batts KP, et al. Impact of cytomegalovirus infection, year of transplantation, and donor age on outcomes after liver transplantation for hepatitis C. Liver Transplantation 2002;8:362-9.

33 Neumann UP, Berg T, Bahra M, et al. Fibrosis progression after liver transplantation in patients with recurrent hepatitis C. J Hepatol 2004;41:830-6.

34 Rifai K, Sebagh M, Karam V, et al. Donor age influences 10-year liver graft histology independently of hepatitis $C$ virus infection. J Hepatol 2004;41:446-53

35 Lake JR, Shorr JS, Steffen BJ, et al. Differential effects of donor age in liver transplant recipients infected with hepatitis $B$, hepatitis $C$ and without viral hepatitis. Am J Transplant 2005;5:549-57.
36 Russo MW, Galanko JA, Zacks SL, et al. Impact of donor age and year of transplant on graft survival in liver transplant recipients with chronic hepatitis C. Am J Transplant 2004;4:1133-8

37 Bizollon T, Palazzo U, Ducerf C, et al. Pilot study of the combination of interferon alfa and ribavirin as therapy of recurrent hepatitis $C$ after liver transplantation. Hepatology 1997;26:500-4.

38 Bizollon T, Ahmed SNS, Radenne S, et al. Long term histological improvement and clearance of intrahepatic hepatitis $C$ virus RNA following sustained response to interferon-ribavirin combination therapy in liver transplanted patients with hepatitis C virus recurrence. Gut 2003;52:283-7.

39 Nair S, Khan S, Loss G, et al. Treatment of recurrent hepatitis $C$ in liver transplant recipients: Is there any histologic benefit? Liver Transplantation 2003;9:354-9.

40 Ahmad J, Dodson SF, Demetris AJ, et al. Recurrent hepatitis $\mathrm{C}$ after liver transplantation: A nonrandomized trial of interferon alfa alone versus interferon alfa and ribavirin. Liver Transplantation $2001 ; 7: 863-9$.

41 Samuel D, Bizollon T, Feray $C$, et al. Interferon- $\alpha 2 b$ plus ribavirin in patients with chronic hepatitis $C$ after liver transplantation: a randomized study. Gastroenterology 2003; 124:642-50.

42 Firpi RJ, Abdelmalek MF, Soldevila-Pico $C$, et al. Combination of interferon alfa- $2 \mathrm{~b}$ and ribavirin in liver transplant recipients with histological recurrent hepatitis C. Liver Transplantation 2002;8:1000-6.

43 De Vera ME, Smallwood GA, Rosado K, et al. Interferon-alpha and ribavirin for the treatment of recurrent hepatitis $\mathrm{c}$ after liver transplantation. Transplantation 2001;71:678-86.

44 Saab S, Hu R, Ibrahim AB, et al. Discordance between ALT values and fibrosis in liver transplant recipients treated with ribavirin for recurrent hepatitis $C$. Am J Transplant 2003;3:328-33.

45 Narayanan Menon KV, Poterucha JJ, El-Amin OM, et al. Treatment of posttransplantation recurrence of hepatitis $C$ with interferon and ribavirin: lessons on tolerability and efficacy. Liver Transplantation 2002;8:623-9.

46 Calne RY, Rolles K, White DJ, et al. Cyclosporin A initially as the only immunosuppressant in 34 recipients of cadaveric organs: 32 kidneys, 2 pancreases, and 2 livers. Lancet 1979; ii: 1033-6.

47 Starzl TE, Klintmalm GB, Porter KA, et al. Liver transplantation with use of cyclosporin a and prednisone. N Engl J Med 1981;305:266-9.

48 Merion RM, White DJ, Thiru S, et al. Cyclosporine: five years' experience in cadaveric renal transplantation. N Engl J Med 1984;310:148-54.

49 Randomised trial comparing tacrolimus (FK506) and cyclosporin in prevention of liver allograft rejection. European FK506 Multicentre Liver Study Group. Lancet 1994:344:423-8.

50 The US Multicenter FK506 Liver Study Group. A comparison of tacrolimus (FK 506) and cyclosporine for immunosuppression in liver transplantation. N Engl J Med 1994;331:1110-15.

51 Rolles K, Davidson BR, Burroughs AK. A pilot study of immunosuppressive monotherapy in liver transplantation: tacrolimus versus microemulsified cyclosporin. Transplantation 1999;68:1195-8.

52 Martin P, Busuttil RW, Goldstein RM, et al. Impact of tacrolimus versus cyclosporine in hepatitis $C$ virus-infected liver transplant recipients on recurrent hepatitis: a prospective, randomized trial. Liver Transplantation 2004; 10:1258-62.

53 Fisher RA, Ham JM, Marcos A, et al. A prospective randomized trial of mycophenolate mofetil with neoral or tacrolimus after orthotopic liver transplantation. Transplantation 1998;66:1616-21.

54 Jain A, Kashyap R, Demetris AJ, et al. A prospective randomized trial of mycophenolate mofetil in liver transplant recipients with hepatitis C. Liver Transplantation 2002;8:40-6.

55 Smallwood G, Davis L, Martinez E, et al. Mycophenolate's influence in the treatment of recurrent hepatitis c following liver transplantation. Transplant Proc 2002;34:1559.

56 Berenguer M. Crippin J, Gish R, et al. A model to predict severe $\mathrm{HCV}$-related disease following liver transplantation. Hepatology 2003;38:34-41

57 Bahra M, Neumann UP, Jacob D, et al. MMF and calcineurin taper in recurrent hepatitis $C$ after liver transplantation: impact on histological course. American Journal of Transplantation 2005:5:406-11.

58 Samonakis DN, Triantos CK, Thalheimer U, et al. Immunosuppression and donor age with respect to severity of HCV recurrence after liver transplantation. Liver Transplantation 2005;1 1:386-95.

59 Rosen HR, Shackleton CR, Higa L, et al. Use of OKT3 is associated with early and severe recurrence of hepatitis $C$ after liver transplantation. Am J Gastroenterol 1997;92:1453-7.

60 Brillanti S, Vivarelli M, De Ruvo N, et al. Slowly tapering off steroids protects the graft against hepatitis $C$ recurrence after liver transplantation. Liver Transplantation 2002:8:884-8.

61 Belli LS, Alberti AB, Vangeli $M$, et al. Tapering off steroids three months after liver transplantation is not detrimental for hepatitis $C$ virus disease recurrence. Liver Transplantation 2003;9:201-2.

62 Berenguer M. Outcome of posttransplantation hepatitis $C$ virus disease - Is it the host, the virus, or how we modify the host and/or the virus? Liver Transplantation 2002;8:889-91

63 Watson CJ, Friend PJ, Jamieson NV, et al. Sirolimus: a potent new immunosuppressant for liver transplantation. Transplantation 1999;67:505-9.

64 Groth CG, Backman L, Morales JM, et al. Sirolimus (rapamycin)-based therapy in human renal transplantation: similar efficacy and different toxicity compared with cyclosporine. Sirolimus european renal transplant study group. Transplantation 1999;67:1036-42. 
65 Mohaupt MG, Vogt B, Frey FJ. Sirolimus-associated eyelid edema in kidney transplant recipients. Transplantation 2001;72:162-4.

66 Murgia MG, Jordan S, Kahan BD. The side effect profile of sirolimus: a phase i study in quiescent cyclosporine-prednisone-treated renal transplant patients. Kidney Int 1996:49:209-16.

67 Blum CB. Effects of sirolimus on lipids in renal allograft recipients: an analysis using the Framingham risk model. Am J Transplant 2002;2:551-9.

68 Guilbeau JM. Delayed wound healing with sirolimus after liver transplant. Ann Pharmacother 2002;36:1391-5.

69 Van Gelder T, Ter Meulen CG, Hene R, et al. Oral ulcers in kidney transplant recipients treated with sirolimus and mycophenolate mofetil. Transplantation 2003;75:788-91.

70 Snell GI, Levvey BJ, Chin W, et al. Sirolimus allows renal recovery in lung and heart transplant recipients with chronic renal impairment. J Heart Lung Transplant 2002;21:540-6.

71 Heffron T, Smallwood G, Davis L, et al. Sirolimus-based immunosuppresive protocol for calcineurin sparing in liver transplantation. Transplant Proc 2002;34:1522-3.
72 Morales JM, Wramner L, Kreis H, et al. Sirolimus does not exhibit nephrotoxicity compared to cyclosporine in renal transplant recipients. Am J Transplant 2002;2:436-42.

73 Zhu J, Wu J, Frizell E, et al. Rapamycin inhibits hepatic stellate cell proliferation in vitro and limits fibrogenesis in an in vivo model of liver fibrosis. Gastroenterology 1999;117:1198-204.

74 Frizell E, Abraham A, Doolittle M, et al. FK506 enhances fibrogenesis in in vitro and in vivo models of liver fibrosis in rats. Gastroenterology 1994;107:492-8.

75 Salas-Prato M, Assalian A, Mehdi AZ, et al. Inhibition by rapamycin of pdgfand bfgf-induced human tenon fibroblast proliferation in vitro. Journal of Glaucoma 1996;5:54-9.

76 Verrill C, Davies J, Maltby J, et al. The Rapamycin analogue everolimus reduces rat stellate cell activation in two different in-vitro models. Hepatology 2003;38(suppl 1):334A.

\section{ANSWERS}

1. F; 2. T; 3. F; 4. F; 5. T.

\section{Clinical Evidence-Call for contributors}

Clinical Evidence is a regularly updated evidence-based journal available worldwide both as a paper version and on the internet. Clinical Evidence needs to recruit a number of new contributors. Contributors are healthcare professionals or epidemiologists with experience in evidence-based medicine and the ability to write in a concise and structured way.

Areas for which we are currently seeking contributors:

- Pregnancy and childbirth

- Endocrine disorders

- Palliative care

- Tropical diseases

We are also looking for contributors for existing topics. For full details on what these topics are please visit www.clinicalevidence.com/ceweb/contribute/index.jsp

However, we are always looking for others, so do not let this list discourage you.

Being a contributor involves:

- Selecting from a validated, screened search (performed by in-house Information Specialists) epidemiologically sound studies for inclusion.

- Documenting your decisions about which studies to include on an inclusion and exclusion form, which we keep on file.

- Writing the text to a highly structured template (about 1500-3000 words), using evidence from the final studies chosen, within 8-10 weeks of receiving the literature search.

- Working with Clinical Evidence editors to ensure that the final text meets epidemiological and style standards.

- Updating the text every 12 months using any new, sound evidence that becomes available. The Clinical Evidence in-house team will conduct the searches for contributors; your task is simply to filter out high quality studies and incorporate them in the existing text.

If you would like to become a contributor for Clinical Evidence or require more information about what this involves please send your contact details and a copy of your CV, clearly stating the clinical area you are interested in, to CECommissioning@bmigroup.com.

\section{Call for peer reviewers}

Clinical Evidence also needs to recruit a number of new peer reviewers specifically with an interest in the clinical areas stated above, and also others related to general practice. Peer reviewers are healthcare professionals or epidemiologists with experience in evidence-based medicine. As a peer reviewer you would be asked for your views on the clinical relevance, validity, and accessibility of specific topics within the journal, and their usefulness to the intended audience (international generalists and healthcare professionals, possibly with limited statistical knowledge). Topics are usually 1500-3000 words in length and we would ask you to review between 2-5 topics per year. The peer review process takes place throughout the year, and out turnaround time for each review is ideally 10-14 days. If you are interested in becoming a peer reviewer for Clinical Evidence, please complete the peer review questionnaire at www. clinicalevidence.com/ceweb/contribute/peerreviewer.jsp 